\title{
Histone deacetylase inhibitor reverses multidrug resistance by attenuating the nucleophosmin level through PI3K/Akt pathway in breast cancer
}

\author{
SI-YING CHEN $^{1}$, XIAO-WEI ZHENG ${ }^{1}$, JIANG-XIA CAI ${ }^{1,2}$, WEI-PENG ZHANG ${ }^{1,3}$, \\ HAI-SHENG YOU ${ }^{1}$, JIAN-FENG XING ${ }^{4}$ and YA-LIN DONG ${ }^{1}$ \\ ${ }^{1}$ Department of Pharmacy, The First Affiliated Hospital of Xi'an Jiaotong University, Xi'an 710061, Shaanxi; \\ ${ }^{2}$ Department of Pharmacy, The People's Hospital of Bayingol Mongolian Autonomous Prefecture, \\ Korla 841000, Xinjiang; ${ }^{3}$ Department of Pharmacy, The Eighth Hospital of Xi'an; \\ ${ }^{4}$ School of Pharmacy, Xi'an Jiaotong University, Xi'an 710061, Shaanxi, P.R. China
}

Received February 15, 2016; Accepted March 26, 2016

DOI: 10.3892/ijo.2016.3528

\begin{abstract}
The development of multidrug resistance (MDR) is the major obstacle in the chemotherapy of breast cancer, and it restricts the application of antitumor drugs in the clinic. Therefore it is urgent to search for ways to reverse MDR and restore sensitivity to chemotherapeutics in breast carcinoma. Currently, histone deacetylase inhibitors (HDACIs) offer a promising strategy for tumor therapy as the effective anticancer drugs. Based on the potential resistant target of nucleophosmin (NPM), the purpose of this study was to explore the reversal effect of a new synthetic histone deacetylase inhibitor, FA17, on MDR in methotrexate-resistant breast cancer cells (MCF-7/ MTX) and xenograft tumors. It was shown that the abnormal expression of NPM induced MDR and inhibited downstream mitochondrial apoptotic pathway by activating PI3K/Akt signaling pathway in MCF-7/MTX cells. The reversal effect and molecular mechanism of FA17 were investigated both in vitro and in vivo. We found that FA17 could significantly reverse resistance and sensitize MCF-7/MTX cells to methotrexate. FA17 obviously enhanced resistant cell apoptosis, inhibited expressions of NPM and efflux transporters. Additionally, FA17 could reverse MDR via inactivating PI3K/Akt pathway and accelerating mitochondrial apoptotic pathway both in MCF-7/MTX cells and in xenograft tumors. Taken together, the novel histone deacetylase inhibitor could effectively reverse drug resistance due to suppressing the activity of NPM and
\end{abstract}

Correspondence to: Professor Ya-Lin Dong, Department of Pharmacy, The First Affiliated Hospital of Xi'an Jiaotong University, 277 Yanta West Road, Xi'an 710061, Shaanxi, P.R. China

E-mail: dongyalin@mail.xjtu.edu.cn

Professor Jian-Feng Xing, School of Pharmacy, Xi'an Jiaotong University, 76 Yanta West Road, Xi'an 710061, Shaanxi, P.R. China

E-mail: xajdxjf@mail.xjtu.edu.cn

Key words: breast cancer, nucleophosmin, multidrug resistance, reversal agent, histone deacetylase inhibitors drug efflux pumps by PI3K/Akt and mitochondrial apoptotic pathway. The above not only indicated the potential applied value of FA17 in reversing MDR and enhancing the sensitivity of chemotherapy, but also confirmed the role of NPM in the development of MDR in breast cancer.

\section{Introduction}

Breast cancer is the most common carcinoma among females, and a major public health issue with $>1.6$ million increased cases and 1.2 million deaths each year in China $(1,2)$. Although surgery, radiotherapy, and chemotherapy could cure a certain percentage of patients, most patients still die of this disease (3). Chemotherapy is one of the predominant strategies in the treatment of breast cancer. However, with the continuous application of antitumor drugs, the emergence of multidrug resistance (MDR) seriously restricts clinical efficacy of chemotherapeutics and results in the failure of chemotherapy (4). Therefore, it is urgent to discover effective resistance-reversal agents that may improve the curative effect of chemotherapy drugs and reverse MDR in breast cancer.

In our previous study, we established the methotrexateresistant breast cancer cells (MCF-7/MTX) and identified nucleophosmin that is a new drug-resistant target related to the MDR of breast cancer (5). Nucleophosmin (NPM, also known as B23, numatrin, or N038) was originally discovered as a non-ribosomal nucleolar phosphoprotein that was located primarily in the nucleoli and shuttled between the nucleoli and cytoplasm during the cell cycle (6). NPM possesses important roles in multiple cellular activities, not only as an important player in ribosome biogenesis but also as a potential regulator for cell growth, proliferation, transformation, and apoptosis (7-9). However, NPM was obviously overexpressed in MCF-7/MTX cells, and it could be a critical factor inducing MDR in the breast carcinoma. There were some studies on the correlation between NPM and MDR. NPM was upregulated in the adriamycin-resistant human bladder cancer cells (10). It could increase the sensitivity of resistant leukemia cells to chemotherapeutic drug and reverse MDR by suppressing the 
level of NPM by shRNA (11). Consequently, it is an important way to decrease MDR of breast cancer by searching for effective reversal agents to reverse drug resistance.

Several studies have reported that NPM was a member of histone chaperones which acted a vital role in the dynamic chromatin organization, gene expression and regulation during different cellular processes. Importantly, NPM also enhanced the acetylation-dependent chromatin transcription and affected histone post-translational modification (12). Certainly, it is well-known that acetylation and deacetylation of histones represented two important histone modifications, while histone acetyl transferase (HAT) and histone deacetylase (HDAC) were two key enzymes to maintain the dynamic equilibrium of histone acetylation. Once this steady-state level was interrupted by overexpression of HDAC, it would generate a malignant tumor and even the occurrence of drug resistance in different cancers $(13,14)$. Therefore, screening histone deacetylase inhibitors (HDACi) with efficiency and low toxicity could suppress tumor cells proliferation caused by histone deacetylation and reverse drug resistance induced by the activity of NPM.

NPM as a newfound drug-resistant target, it plays a vital role in the development and progression of MDR in breast cancer. In this study, the relationship between abnormal expression of NPM and activation of PI3K/Akt signaling pathway was addressed. Then, a novel synthetic histone deacetylase inhibitor FA17 (Fig. 1A), possessing tumor suppressor function (15), was used to reverse MDR by reducing the activity of NPM in breast cancer. The reversal effect and molecular mechanism of FA17 were investigated in vitro and in vivo. Taken together, our results indicated that the novel histone deacetylase inhibitor displayed intense reversal activity in the MDR of breast cancer. FA17 would be expected to become an effective drug candidate for reversing MDR in clinical trials.

\section{Materials and methods}

Chemicals and reagents. Methotrexate was obtained from Pude Pharmaceutical Company Ltd. (Shanxi, China). The novel synthetic histone deacetylase inhibitor (FA17) was kindly provided by Professor Jie Zhang from Health Science Center of Xi'an Jiaotong University. Verapamil was purchased from China Pharmaceutical Biological Products Analysis Institute. The Annexin V FLUOS staining kit was purchased from Invitrogen (USA). The primary antibodies against NPM, breast cancer resistance protein (BCRP), dihydrofolate reductase (DHFR), Bcl-2 and Bax were from Epitomics (USA), while phosphatase and tensin homolog deleted on chromosome 10 (PTEN), total Akt (t-Akt), phospho-Akt (p-Akt), caspase-9, caspase-3, and poly(ADP-ribose) polymerase (PARP) antibodies were purchased from Cell Signaling Technology (USA). P-glycoprotein (P-gp) and reduced folate carrier (RFC) antibodies were obtained from Abcam (UK), and multidrug resistance associated protein 1 (MRP1) was from GeneTax (USA). The $\beta$-actin antibody was purchased from Biosynthesis Biotechnology and the horseradish peroxidase-conjugated goat anti-rabbit IgG was from Cwbiotech (Beijing, China).

Cell lines and cell culture. The MCF-7/S sensitive human breast cancer cell line was obtained from Shanghai Institute of

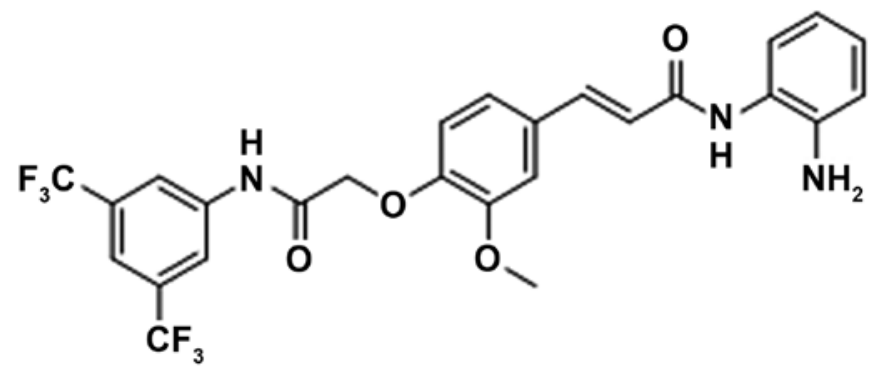

Figure 1. Chemical structure of histone deacetylase inhibitor FA17.

Cell Biology in the Chinese Academy of Sciences (Shanghai, China). The methotrexate-resistant breast cancer cell line (MCF-7/MTX) was successfully established as previously described (5) with the concentration of $220 \mathrm{nM}$ MTX. Both cell types were cultured in RPMI-1640 medium (Gibco, USA) supplemented with $10 \%$ fetal bovine serum (PAA, Austria) and $1 \%$ penicillin/streptomycin in a humidified atmosphere of $5 \% \mathrm{CO}_{2}$ at $37^{\circ} \mathrm{C}$.

Western blot analysis. Protein samples were extracted from whole-cell, the protein concentration was detected by BCA reagent (Beyotime, China) and then separated by 10 or $12 \%$ sodium dodecyl sulfate-polyacrylamide gels and transferred onto polyvinylidene difluoride membranes (Millipore, USA). Then the membranes were blocked with $5 \%$ fat-free milk at room temperature for $2 \mathrm{~h}$, and incubated with diluted antibodies NPM (1:1,000, ab109546), PTEN (1:1,000, \#9188), p-Akt (1:800, \#4090), t-Akt (1:1000, \#4691), Bcl-2 (1:2,500, \#1017-1), Bax (1:2,500, \#1063-1), caspase-9 (1:800, \#9502), caspase-3 (1:800, \#9662), PARP (1:800, \#9542), P-gp (1:500, ab98322), MRP1 (1:600, GTX116046), BCRP (1:800,\#3765-1), RFC (1:1,500, ab62302), DHFR (1:20,000, ab124814) and $\beta$-actin $\left(1: 800\right.$, bs-0061R) overnight at $4^{\circ} \mathrm{C}$. The second antibody conjugated to horseradish peroxidase incubation was developed at room temperature for $2 \mathrm{~h}$. Protein bands were tested using the SuperSignal West Pico kit (Pierce, Thermo Scientific). All samples were performed in triplicates and the protein expression was analyzed using a quantitative analysis system (Image-Pro Plus).

Small interfering RNA transfection. For in vitro knockdown experiments, the double-stranded small interfering RNA (siRNA) against human NPM1 and non-specific siRNA (control siRNA) were purchased from Shanghai GenePharma Company Ltd. (China). They were used for transient transfection as previously described (5). MCF-7/MTX cells were seeded at a density of $5 \times 10^{5}$ per well into a 6 -well plate and cultured in the medium until cell confluence reached $\sim 40 \%$. The following day, cells were transfected with $50 \mathrm{nM} \mathrm{NPM1}$ siRNA and Lipofectamine 2000 reagent (Invitrogen) according to the manufacturer's instructions.

Quantitative real-time PCR analysis. Total cellular mRNA was extracted using RNAfast2000 kit (Fastagen) and reverse transcription to cDNA was performed using PrimeScript RT Master Mix Perfect Real-Time kit (Takara). Quantitative real-time PCR (qRT-PCR) was conducted using SYBR Premix 
Table I. The primers used in qRT-PCR.

\begin{tabular}{lllr}
\hline Gene & \multicolumn{1}{c}{ Forward primer $\left(5^{\prime} \rightarrow 3^{\prime}\right)$} & \multicolumn{1}{c}{ Reverse primer $\left(5^{\prime} \rightarrow 3^{\prime}\right)$} & Product size $(\mathrm{bp})$ \\
\hline$N P M$ & TGGCAGTGGAGGAAGTCTCT & ATCAAACACGGTAGGGAAAGTT & 141 \\
$M D R 1$ & GAGCCCATCCTGTTTGACTG & GCTGCCCTCACAATCTCTTC & 92 \\
$M R P 1$ & AAGGTGGACGAGAACCAGAA & AACAGGGCAGCAAACAGAAC & 110 \\
$B C R P$ & AGCAGGGACGAACAATCATC & GCCAATAAGGTGAGGCTATCA & 82 \\
$R F C$ & TCCTGTCCATCATCTACTTCTTG & AGTGCCTGTGCTGCCTTCT & 130 \\
$D H F R$ & TCTCCAAGACCCCAACTGAG & ATGTGAAAAGCCCGACAAT & 109 \\
$\beta$ - actin & TGACGTGGACATCCGCAAAG & CTGGAAGGTGGACAGCGAGG & 205 \\
\hline
\end{tabular}

Ex Taq II (Takara) and the primer sequences and product lengths are listed in Table I. The assay was performed on the Bio-Rad CFX96 ${ }^{\mathrm{TM}}$ Real-time system with the following procedure: $95^{\circ} \mathrm{C}$ for $30 \mathrm{sec} ; 95^{\circ} \mathrm{C}$ for $5 \mathrm{sec}$ and $60^{\circ} \mathrm{C}$ for $30 \mathrm{sec}$ (40 cycles); and $95^{\circ} \mathrm{C}$ for $15 \mathrm{sec}, 60^{\circ} \mathrm{C}$ for $30 \mathrm{sec}, 95^{\circ} \mathrm{C}$ for $15 \mathrm{sec}$. Each sample was normalized on the basis of $\beta$-actin. Three independent experiments were run to analyze the gene expressions and each sample was repeated in triplicate.

Drug sensitivity assays. The cell viability under drug treatment was measured using MTT assay. Cells were seeded at a density of $5 \times 10^{4}$ per well into 96 -well plates and treated with cytotoxic agents at increasing concentrations for 72 -h incubation, then MTT $(5 \mathrm{mg} / \mathrm{ml})$ was added to each well for an additional $4 \mathrm{~h}$. After discarding the medium, the blue formazan was dissolved in $150 \mu 1$ of DMSO. The absorbance was tested at $490 \mathrm{~nm}$ on a microplate reader (BioTek, USA). The resistance factor (RF) was calculated using the equation: $\mathrm{RF}=\left(\mathrm{IC}_{50}\right.$ value of MCF-7/ $\mathrm{MTX}) /\left(\mathrm{IC}_{50}\right.$ value of MCF-7/S). The data represent three independent experiments.

Reversal effect assays. The reversal effect of FA17 on methotrexate resistance was evaluated in MCF-7/MTX cells using MTT assay. MCF-7/MTX cells were seeded at a density of $5 \times 10^{4}$ per well into 96 -well plates for $24 \mathrm{~h}$, then methotrexate at increasing concentrations in combination with FA17 were added and cultured for $72 \mathrm{~h}$. The reversal index (RI) was calculated using this equation: $\mathrm{RI}=\mathrm{IC}_{50}$ of methotrexate $/ \mathrm{IC}_{50}$ of methotrexate plus FA17. The data represent three independent experiments.

Flow cytometry assays. For the cell cycle assay, cells were harvested after treatment and fixed in $70 \%$ cold ethanol at $4^{\circ} \mathrm{C}$ overnight. After suspension with PBS, cells were stained with RNase at $37^{\circ} \mathrm{C}$ for 15 min and with propidium iodide on ice for $30 \mathrm{~min}$ away from light. Then cell cycle distribution was detected immediately using flow cytometry (BD Bioscience, USA).

Cell apoptosis was measured by Annexin V FLUOS staining kit according to the manufacturer's instructions. Cells from different samples were analyzed for live, necrotic, early and late apoptotic cells by flow cytometry. All experiments were run in triplicate.

In vivo tumor xenograft model and immunohistochemistry. Female BALB/c nude mice (18 \pm 4 g, 4- 6 weeks) were purchased from Shanghai Laboratory Animal Center of the Chinese Academy of Sciences. All animal experiments were carried out in accordance with guidelines and approval of the Institutional Animal Care and Use Committee of Xi'an Jiaotong University. MCF-7/MTX cells ( $200 \mu 1,1 \times 10^{7}$ cells) were injected subcutaneously into mice, and when they all developed tumors with a size $\sim 100 \mathrm{~mm}^{3}$, mice were randomly assigned into four groups $(\mathrm{n}=6)$ and treated intraperitoneally with vehicle, MTX $(9 \mathrm{mg} /$ $\mathrm{kg})$, FA17 $(10 \mathrm{mg} / \mathrm{kg})$ or in combination every three days for a total of three weeks. Tumor volume was measured on alternate day and calculated with the formula $\mathrm{a} \mathrm{x}^{2} / 2$ (a, the largest diameter; $b$, the smallest diameter), additionally, mouse weight was monitored three times per week. Upon termination, mice were sacrificed and tumors were harvested. Protein were exacted from tumors for western blot analysis. The other tumor tissues were fixed with formalin and embedded with paraffin, which were analyzed for regular hematoxylin and eosin (H\&E) stain and immunohistochemistry. These tissue sections were incubated with primary antibody (NPM, 1:200 dilution), and control group with PBS. The immunostaining intensities or percentages of positive cells were evaluated as previously described under bright-field microscopy (16). Images from 6 random fields of each section were used for quantitative analysis (Image-Pro Plus).

Statistical analysis. All data were expressed as mean \pm standard deviation (SD). Statistical analyses were performed using one-way ANOVA, and P-value $<0.05$ was considered as statistical significance.

\section{Results}

NPM overexpression activates PI3K/Akt pathway and suppresses cell apoptosis. Our previous study identified that NPM was significantly overexpressed in the MCF-7/MTX cells, and served as a novel drug-resistant target in breast cancer using proteomics technology (5). Similarly, some reports found upregulation of NPM accounted for MDR phenotype in various cancers $(10,11,17)$. In addition, PI3K/Akt signaling pathway played a significant role in carcinogenesis and development of malignant tumors, so activation of this pathway emerged in a majority of tumors and even facilitated the formation of drug-resistance (18-21). We detected NPM and related factors of PI3K/Akt signaling pathway both in MCF-7/S and MCF-7/ MTX cells by western blotting. As shown in Fig. 2A and B, NPM was obviously overexpressed in MCF-7/MTX cells 
A
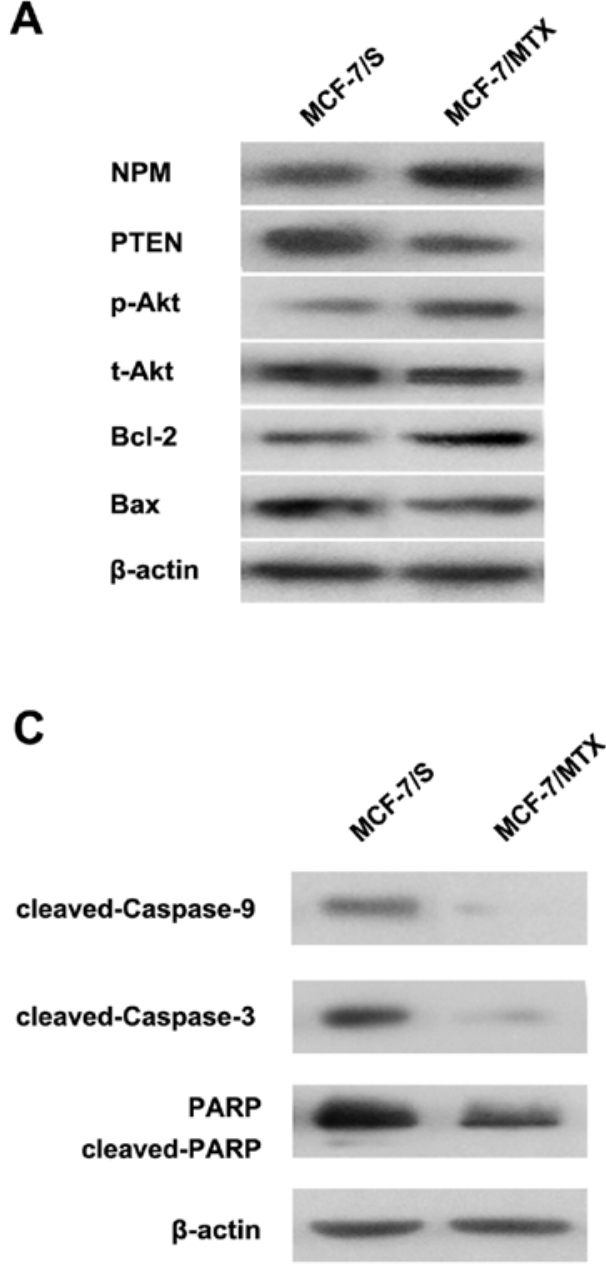

B
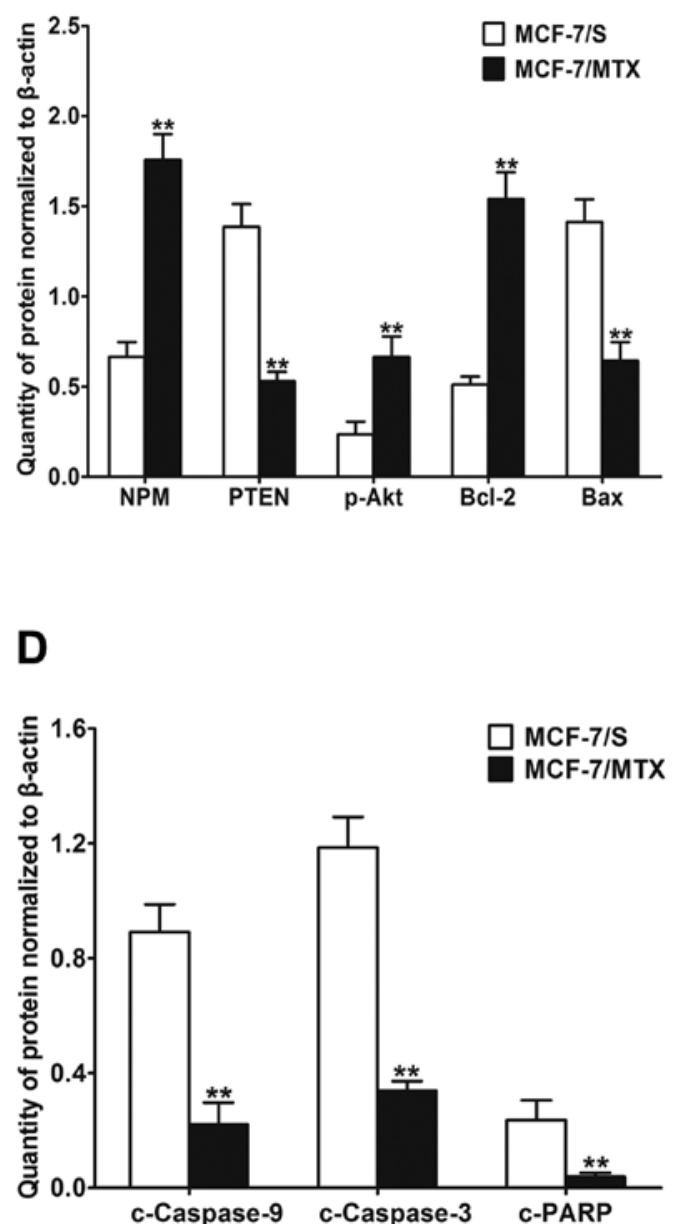

Figure 2. The activation of PI3K/Akt pathway and inhibition of cell apoptosis in MCF-7/MTX cells. Western blot detection (A) and quantitative analysis (B) of NPM and PI3K/Akt pathway factors PTEN, p-Akt, t-Akt, Bcl-2 and Bax in MCF-7/S and MCF-7/MTX cells. The expression of mitochondrial apoptosis pathway related factors cleaved-caspase-9, cleaved-caspase-3 and cleaved-PARP were detected (C) and analyzed (D) by western blotting in MCF-7/S and MCF-7/MTX cells. Relative protein expression is presented as mean $\pm \mathrm{SD}, \beta$-actin was used as loading control, ${ }^{*} \mathrm{P}<0.05,{ }^{* * *} \mathrm{P}<0.01$ by ANOVA versus control group.

compared with MCF-7/S cells. The decreased PTEN level and increased p-Akt expression were both observed in MCF-7/ MTX cells, which indicated the PI3K/Akt pathway was activated in MCF-7/MTX cells. Furthermore, the downstream pro-survival factor Bcl-2 was upregulated and pro-apoptotic factor Bax was downregulated, which significantly suppressed cells apoptosis in MCF-7/MTX cells.

To better understand the effect of drug resistance on cell apoptosis, the interrelated factors of mitochondrial apoptosis pathway were also investigated. As Akt augments phosphorylation, the downstream apoptotic molecules including cleaved-caspase-9, cleaved-caspase-3 and cleaved-PARP were all downregulated in MCF-7/MTX cells (Fig. 2C and D). The above demonstrated that NPM-induced resistance not only activated PI3K/Akt pathway, but also inhibited the apoptotic function of resistant cells.

Silencing of NPM inhibits the PI3K/Akt pathway in MCF-7/ MTX cells. To further explore the interaction of NPM and PI3K/Akt pathway, we determined the changes in expression of related factors after knockdown of NPM. We predicted that the reduction of NPM could restrain the PI3K/Akt pathway and accelerate its downstream pro-apoptotic effect. Decreasing NPM expression by siRNA in MCF-7/MTX cells, mRNA level of NPM was reduced by $>70 \%$ compared with the siRNA controls (Fig. 3A). Additionally, decreasing NPM expression could accelerate upregulation of PTEN and attenuate Akt phosphorylation while t-Akt was not apparently changed in siNPM-resistant cells. Then the expression of downstream pro-apoptotic factor Bax was elevated, and the pro-survival factor Bcl-2 was remarkably decreased (Fig. 3B and $\mathrm{C}$ ). Moreover, mitochondrial apoptosis molecules cleaved-caspase-9, cleaved-caspase- 3 and cleaved-PARP were all increased (Fig. 3D and E). These results declared that function of pro-apoptosis was elevated by devitalizing PI3K/Akt pathway with NPM knockdown in MCF-7/MTX cells.

The intrinsic cytotoxicity of FA17 on MCF-7/S and MCF-7/ MTX cells. A novel synthetic histone deacetylase inhibitor FA17 was reported to display a promising profile as an antitumor candidate (15), but whether or not FA17 could reverse 
A

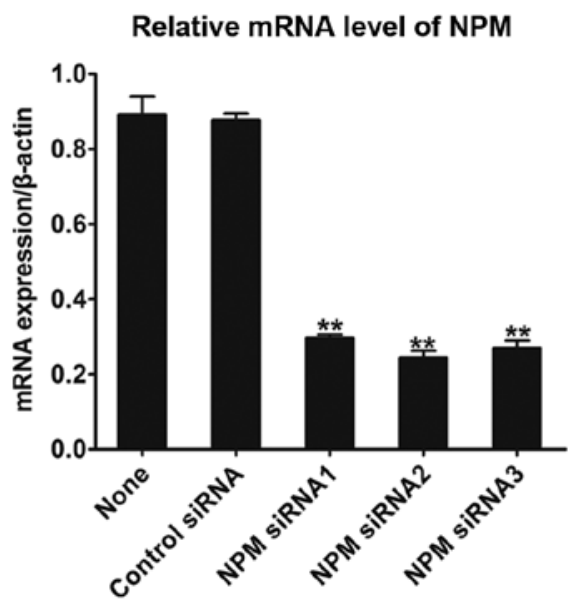

B

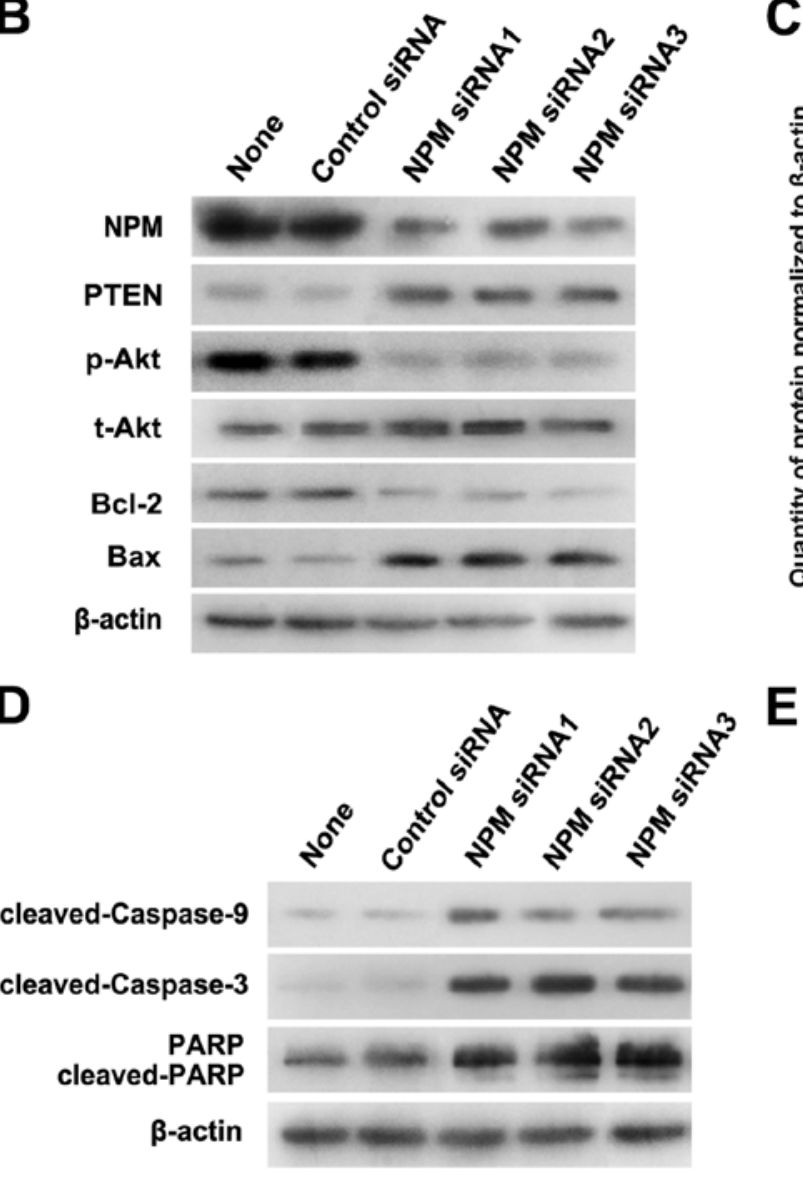

$\mathbf{E}$
Relative protein expression
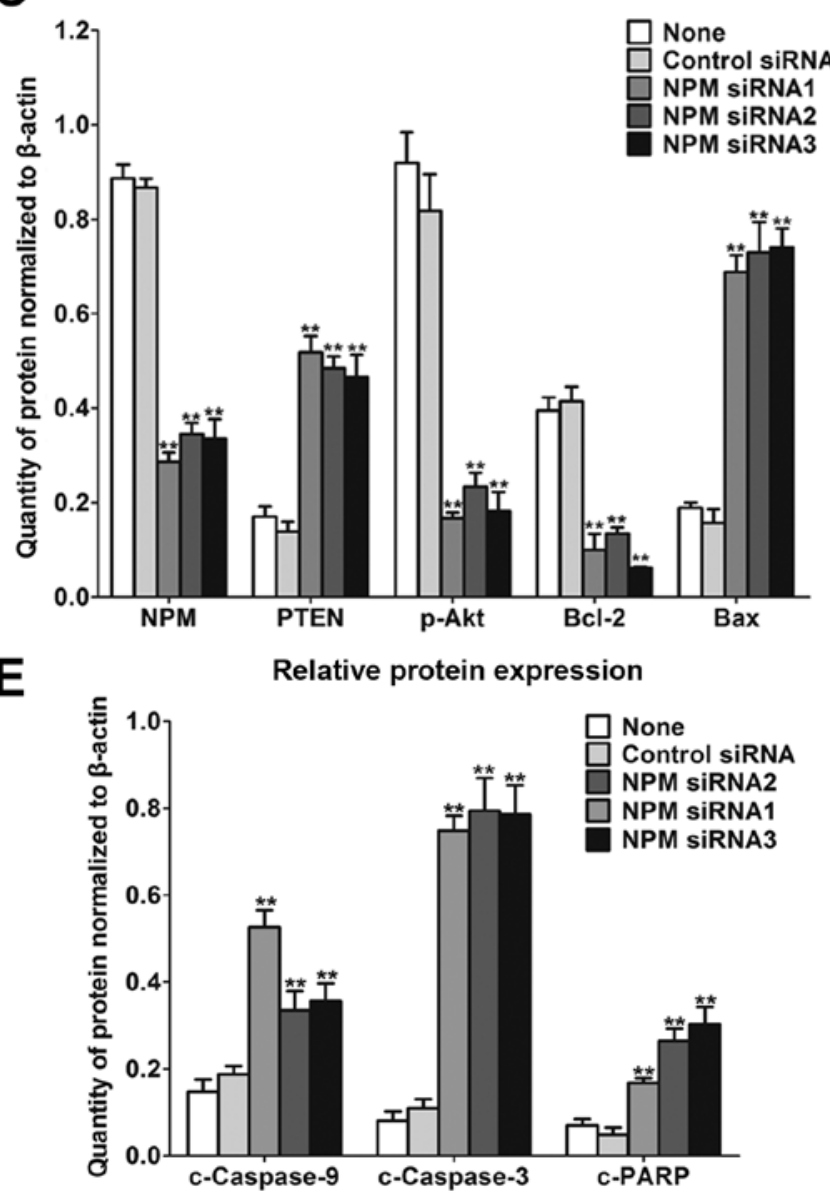

Figure 3. Knockdown of NPM inactivates PI3K/Akt pathway and induces resistant cells apoptosis. (A) The gene expression of NPM in MCF-7/MTX cells transfected with NPM siRNA or control siRNA by qRT-PCR. Immunoblotting (B) and quantitative analysis (C) of NPM, PTEN, p-Akt, t-Akt, Bcl-2 and Bax expressions in MCF-7/MTX cells transfected with TAGLN2 siRNA or control siRNA. Mitochondrial apoptosis molecules cleaved-caspase-9, cleavedcaspase-3, and cleaved-PARP levels were detected (D) and quantitatively analyzed (E) in MCF-7/MTX cells transfected with NPM siRNA or control siRNA. Relative protein expressions were presented as mean $\pm \mathrm{SD}, \beta$-actin was loading control, ${ }^{*} \mathrm{P}<0.05,{ }^{* *} \mathrm{P}<0.01$ by ANOVA versus control group.

breast cancer MDR was not clear. We detected intrinsic cytotoxicity of FA17 in MCF-7/S and MCF-7/MTX cells by MTT analysis. As shown in Fig. 4A, FA17 obviously inhibited growth of sensitive and resistant cells in a dose-dependent manner, and $\mathrm{IC}_{50}$ was $16.6 \pm 2.43$ and $23.4 \pm 2.23 \mu \mathrm{M}$, respectively, these data indicated that MCF-7/MTX cells did not produce resistance to FA17 which may serve as a candidate chemicals to reverse MDR.
FA17 reverses drug resistance in MCF-7/MTX cells. The reversal effect of FA17 on the MDR of MCF-7/MTX cells was analyzed by MTT assay. Three concentrations including $0.85,1.7$ and $3.4 \mu \mathrm{M}$ under the lower-toxic dose (inhibition rate $<15 \%$ ) were chosen to evaluate efficacies of FA17 on NPM-mediated methotrexate resistance in breast cancer cells, and verapamil was used as a positive control. The results are presented in Table II, RIs of these three doses to MCF-7/MTX 
A

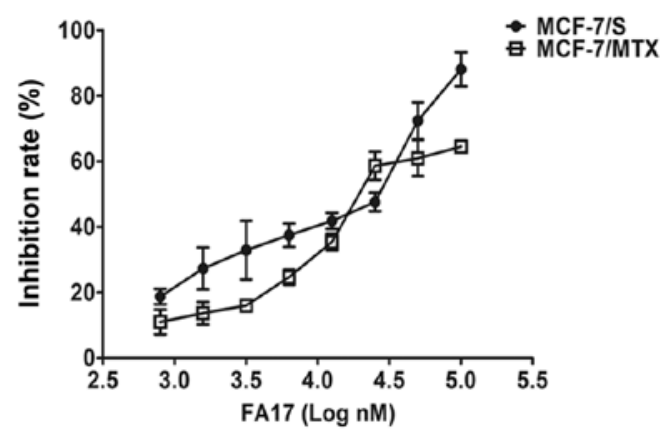

B

Control
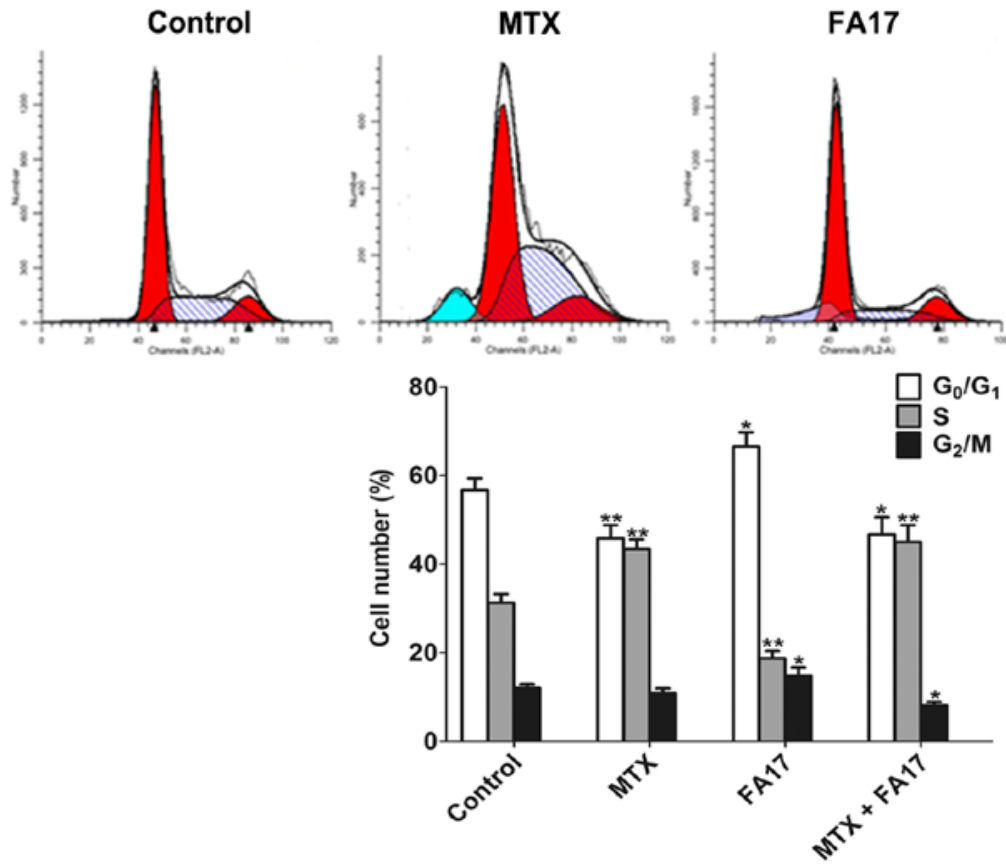

C

D

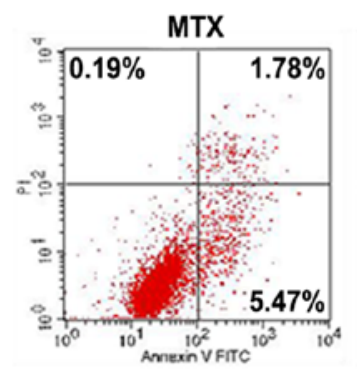

E
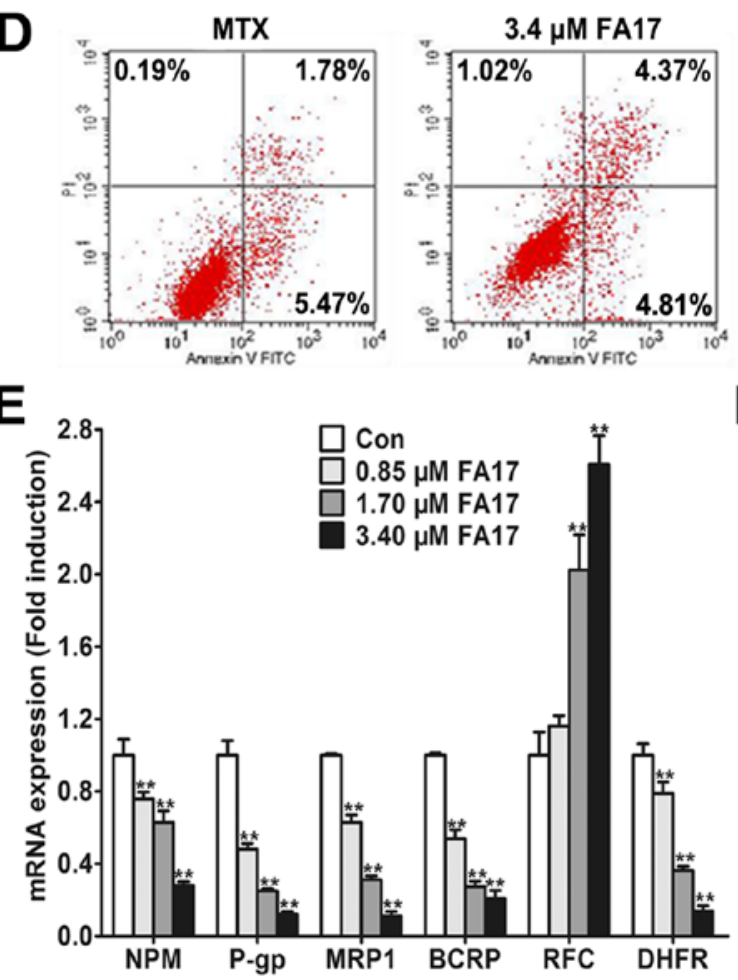

FA17
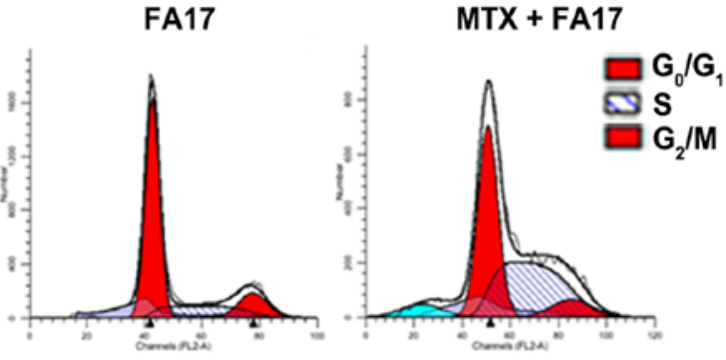
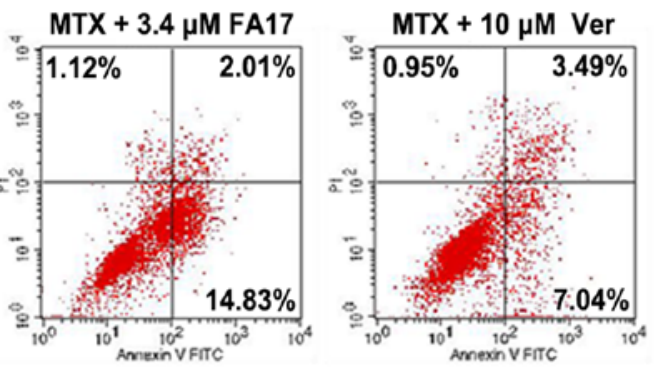

F

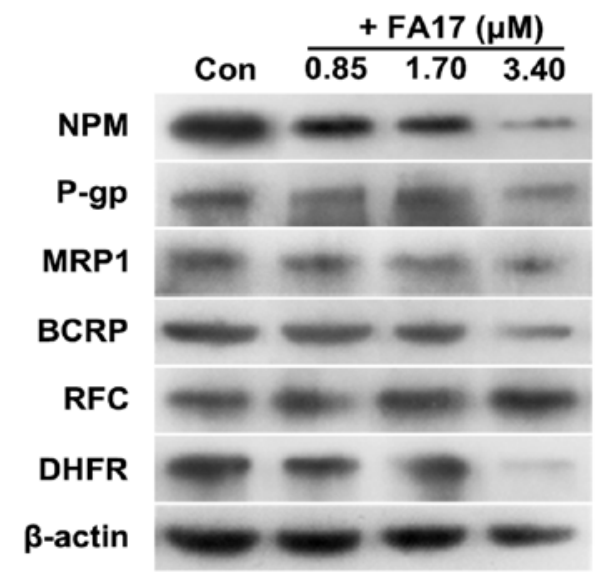

Figure 4. The reverse effect of FA17 on MDR in MCF-7/MTX cells. (A) The cytotoxicity of FA17 to MCF-7/S and MCF-7/MTX cells. Cells were treated with indicated doses of FA17, and cell viability was assessed by MTT method. (B) The cell cycle of MCF-7/MTX cells treated with methotrexate or FA17 alone and combined treatment, respectively (C), DNA content of cells was determined by flow cytometry. (D) The cell apoptosis rate of MCF-7/MTX cells treated with methotrexate or FA17 and combined group for $48 \mathrm{~h}$. Cells were stained with Annexin V-FITC/PI and analyzed by flow cytometry. Verapamil was used as a positive control. The qRT-PCR (E) and western blot analysis (F) of NPM, P-gp, MRP1, BCRP, RFC and DHFR levels treated with indicated concentrations of FA17 in MCF-7/MTX cells. Data are presented as mean $\pm \mathrm{SD},{ }^{*} \mathrm{P}<0.05,{ }^{* *} \mathrm{P}<0.01$ by ANOVA versus control group. 
Table II. Effect of FA17 on $\mathrm{IC}_{50}$ values of methotrexate in MCF-7/MTX cells.

\begin{tabular}{lcrc}
\hline Group & Concentration $(\mu \mathrm{M})$ & $\mathrm{IC}_{50}$ of MTX $(\mathrm{nM})$ & $\mathrm{RI}$ \\
\hline Control & & $2,818 \pm 97.9$ & 1.00 \\
FA17 & 0.85 & $1,084 \pm 87.5$ & 2.60 \\
& 1.70 & $741.3 \pm 80.2$ & 3.80 \\
& 3.40 & $642.7 \pm 32.6$ & 4.38 \\
Verapamil $^{\mathrm{a}}$ & 10 & $562.3 \pm 90.3$ & 5.01 \\
\hline
\end{tabular}

${ }^{\mathrm{a}}$ Verapamil was used as a positive control.

cells was $2.60,3.80$ and 4.38 , respectively, thus, the effect of FA17 higher concentration was close to verapamil and its dose was markedly less than control. This phenomenon demonstrated strong reversal activity of FA17 in MCF-7/MTX cells.

To further investigate effects of FA17 on cell cycle, MCF-7/MTX cells were treated with methotrexate $(2 \mu \mathrm{M})$, FA17 $(3.4 \mu \mathrm{M})$, and two drug combinations using flow cytometry for cell-cycle detection. Compared with control, methotrexate and combination group caused a significant decrease of cells in the $G_{0} / G_{1}$ phase and a corresponding increased proportion of S-phase cells, while FA17 alone treatment apparently added $\mathrm{G}_{0} / \mathrm{G}_{1}$-phase cells and reduced S-phase cells (Fig. 4B and C). The experimental results revealed that the role of methotrexate and combination treatment blocked S-phase cells, but $\mathrm{G}_{0} / \mathrm{G}_{1}$-phase arrest appeared in the FA17 group.

In addition, to assess the effect of FA17 on methotrexate induced resistance, an apoptosis assay was performed in MCF-7/MTX cells treated with methotrexate or FA17 alone and combination group, verapamil was used as a positive control again. Treatment of cells with FA17 and combination groups significantly increased cells apoptosis rates compared with methotrexate group, and FA17 strengthened methotrexate-induced MCF-7/MTX cell apoptosis, its intensity was apparently greater than the effect of positive drug verapamil (Fig. 4D). Thus it was proven that FA17 had the ability to induce resistant cell apoptosis, while increasing the sensitivity of MCF-7/MTX cells to methotrexate.

As previous studies have demonstrated that NPM, membrane transport proteins including P-gp, MRP1, BCRP and methotrexate resistance-associated RFC and DHFR all had abnormal expression in resistant cells (5), we determined if resistant factors were modulated by FA17 in MCF-7/MTX cells using qRT-PCR and western blot assays. After 48-h treatment, both mRNA and protein expressions of NPM, P-gp, MRP1, BCRP, DHFR were downregulated while RFC level was upregulated in MCF-7/MTX cells (Fig. 4E and F). The results validated that FA17 levels partially reversed MDR characteristics of MCF-7/MTX cells at gene and protein levels.

Reversal mechanism of FA17 in MCF-7/MTX cells. We have discovered that the occurrence of drug resistance was correlated with the activation of PI3K/Akt pathway, however, to clarify whether FA17 reversed methotrexate-induced breast cancer resistance by PI3K/Akt pathway, we determined expressions of PTEN, Akt and downstream mitochondrial apoptosis related factors with western blotting. As shown in Fig. 5A and B, Akt phosphorylation was suppressed along with the intensifying of PTEN level, and it emerged evidently in a dose-dependent manner, then enervated relevant factor Bcl-2 level and enhanced Bax expression, which eventually reduced MDR phenotype of MCF-7/MTX and induced cell apoptosis.

Next, we investigated the inhibitory effect of FA17 on apoptotic process of resistant cells, the variation of mitochondrial apoptosis signaling pathway molecule expression was detected in MCF-7/MTX cells. As expected, caspase-9, caspase-3, and PARP proteins obvious cleaving belts depended on the dose under FA17 treatment (Fig. 5C and D), which predicted appearance of cells apoptosis. Taken together, these results illuminated that FA17 may reverse drug resistance of MCF-7/ MTX cells through inhibiting the activation of PI3K/Akt and accelerating mitochondrial apoptosis.

FA17 significantly reverses methotrexate resistance in vivo. Our research has suggested that FA17 reversed MDR of MCF-7/ MTX cells by PI3K/Akt pathway in vitro. To further confirm this effect in vivo, we evaluated FA17 alone or combined with methotrexate treatment in nude mouse xenograft model when tumors were palpable and continued for 14 days. Animals bearing MCF-7/MTX cells displayed a tumor growth profile (Fig. 6A and B), comparing with controls, tumor volumes were significantly decreased after methotrexate and FA17 combined treatment, and Table III shows the most effective in attenuating tumor burden (51\% tumor growth inhibition), whereas methotrexate or FA17 alone group also possessed a certain

Table III. The inhibition of FA17 on nude mouse xenografted tumors of MCF-7/MTX cells.

\begin{tabular}{|c|c|c|c|c|c|c|c|}
\hline \multirow[b]{2}{*}{ Group } & \multicolumn{2}{|c|}{ Body weight (g) } & \multicolumn{2}{|c|}{ Tumor volume $\left(\mathrm{mm}^{3}\right)$} & \multirow[b]{2}{*}{$\begin{array}{c}\text { Tumor } \\
\text { weight }(\%)\end{array}$} & \multirow[b]{2}{*}{$\begin{array}{l}\text { Growth rate of } \\
\text { body weight }(\mathrm{g})\end{array}$} & \multirow[b]{2}{*}{$\begin{array}{r}\text { Inhibition } \\
\text { rate }(\%)\end{array}$} \\
\hline & Initial & Final & Initial & Final & & & \\
\hline Control & $18.5 \pm 0.98$ & $21.3 \pm 1.28$ & $130 \pm 30$ & $1,320 \pm 420$ & $1.34 \pm 0.29$ & 15.14 & \\
\hline MTX & $18.5 \pm 1.06$ & $20.8 \pm 1.02$ & $120 \pm 20$ & $1,020 \pm 280$ & $0.98 \pm 0.31$ & 10.85 & 19.40 \\
\hline FA17 & $18.4 \pm 1.12$ & $20.5 \pm 0.91$ & $110 \pm 20$ & $890 \pm 240$ & $0.79 \pm 0.25^{\mathrm{a}}$ & 11.41 & 29.10 \\
\hline MTX + FA17 & $19.6 \pm 1.27$ & $20.9 \pm 0.87$ & $130 \pm 20$ & $590 \pm 140^{\mathrm{a}}$ & $0.45 \pm 0.21^{\mathrm{b}}$ & 6.63 & 51.49 \\
\hline
\end{tabular}

${ }^{\mathrm{a}} \mathrm{P}<0.05 ;{ }^{\mathrm{b}} \mathrm{P}<0.01$ versus control. 
A

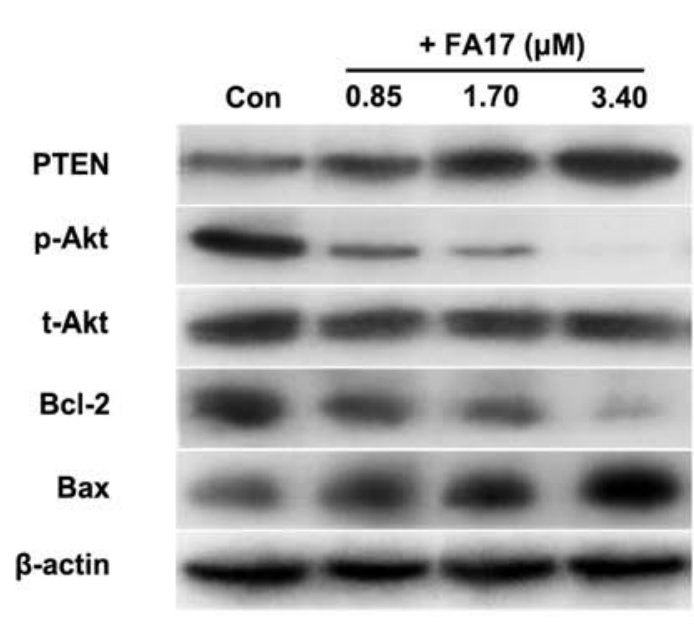

C

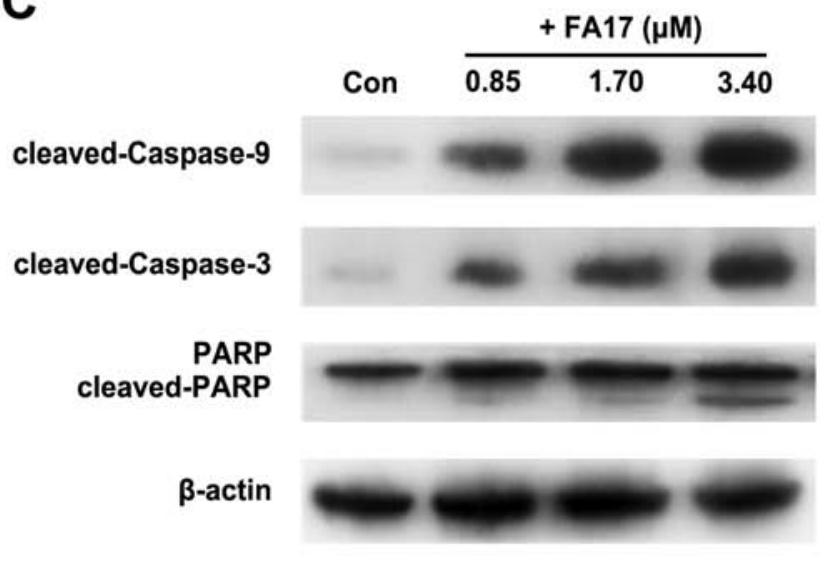

B

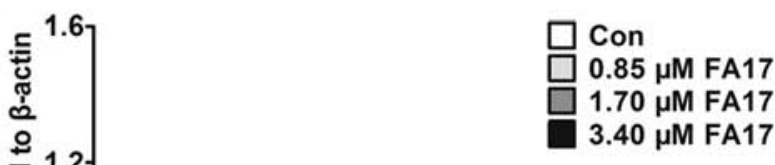

D

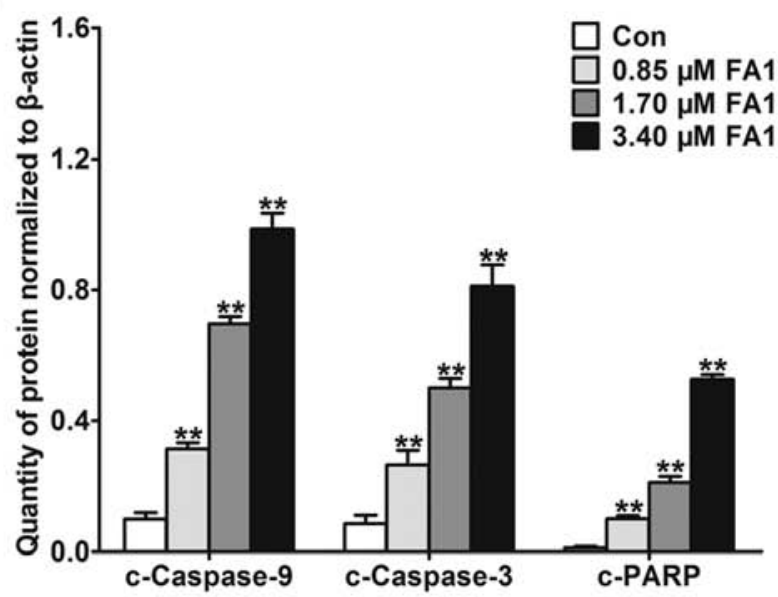

Figure 5. The reversal mechanism of FA17 in MCF-7/MTX cells. Determination (A) and quantitative analysis (B) of PI3K/Akt pathway related molecule expression under dose response in FA17 in MCF-7/MTX cells. Immunoblotting examining (C) and analyzing (D) the effectiveness of FA17 on mitochondria apoptosis pathway in MCF-7/MTX cells. Relative values represent the mean $\pm \mathrm{SD}, \beta$-actin was used as loading control, ${ }^{*} \mathrm{P}<0.05$, ** $\mathrm{P}<0.01$ by ANOVA vs. control group.

degree of suppression of tumor growth, and inhibition rates were 19 and 29\%, respectively. In addition, it did not cause conspicuous reduction in body weight and any other abnormities under drug therapy.

To further explore influence of FA17 and methotrexate treatment on tumor tissues of nude mice, H\&E staining was performed to observe morphological variations and immunohistochemical analysis was applied to detect NPM expression. As shown in Fig. 6C, tumor necrosis and histomorphology of tumor tissues were not obviously observed after drug treatment. Whereas, NPM expression was strongly positive in the control group, and its level was downregulated in methotrexate or FA17 alone group, but NPM showed almost negative expression in the combined treatment (Fig. 6D). These results manifested that methotrexate and FA17 combined therapy significantly inhibited drug-resistant target NPM and lowered resistance of nude mice.

To clarify the underlying resistance mechanism of combination where methotrexate and FA17 are more effective than either drug alone, we next detected expressions of PI3K/Akt pathway related factors. The immunoblotting revealed that intensity of PTEN was augmented under drug treatment accompanied by downregulation of NPM level, especially in the combined group. Furthermore, drug action inhibited Akt phosphorylation and downstream Bcl-2 expression, and reinforced the role of Bax, which led to resistant tumor cells apoptosis, eventually blocking the growth of methotrexateresistant tumors in nude mice (Fig. 6E and F). These experiments clarified the molecular mechanism by which FA17 reversed MDR of breast cancer in vivo.

\section{Discussion}

The chemotherapy of breast carcinoma remains a challenging problem and the reason is drug resistance, due to the multifarious application of chemotherapeutic agents in clinical (22). However, breast cancer resistance is a multistep process involving alterations of certain relevant genes and proteins and activation of various signaling pathways $(23,24)$. Consequently, there is an urgent need to discover new therapeutic targets so that the novel therapeutic agents can be developed to enhance the effectiveness of treatment while reducing adverse side reactions (25-27). Our previous study found that NPM was abnormally overexpressed in MCF-7/MTX cells compared 
A

MTX

FA17

MTX + FA17

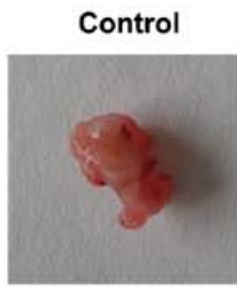

B

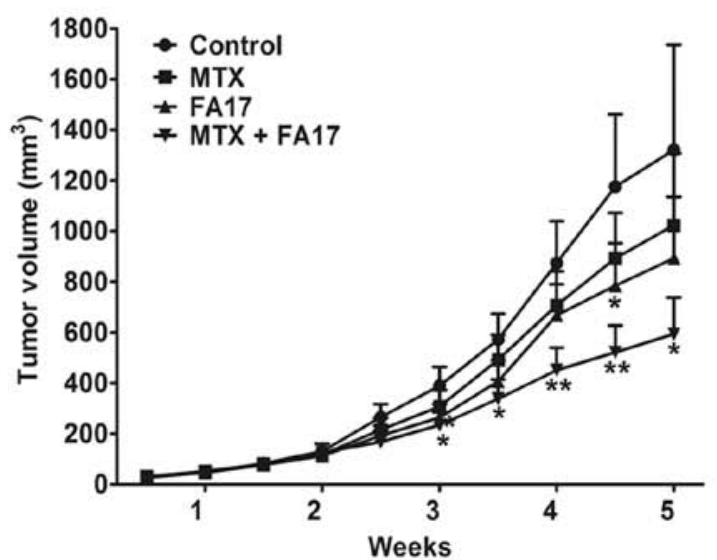

C
Control

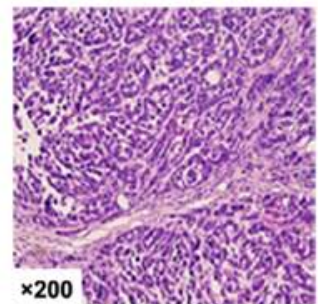

D Control

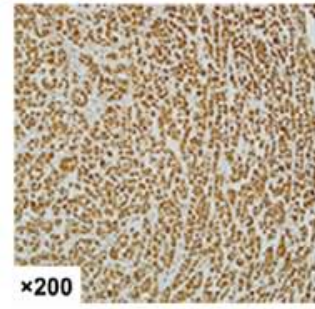

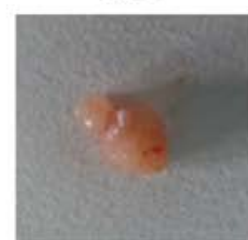
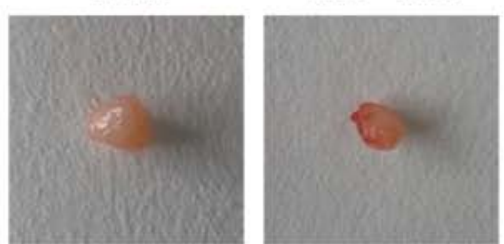

Weeks
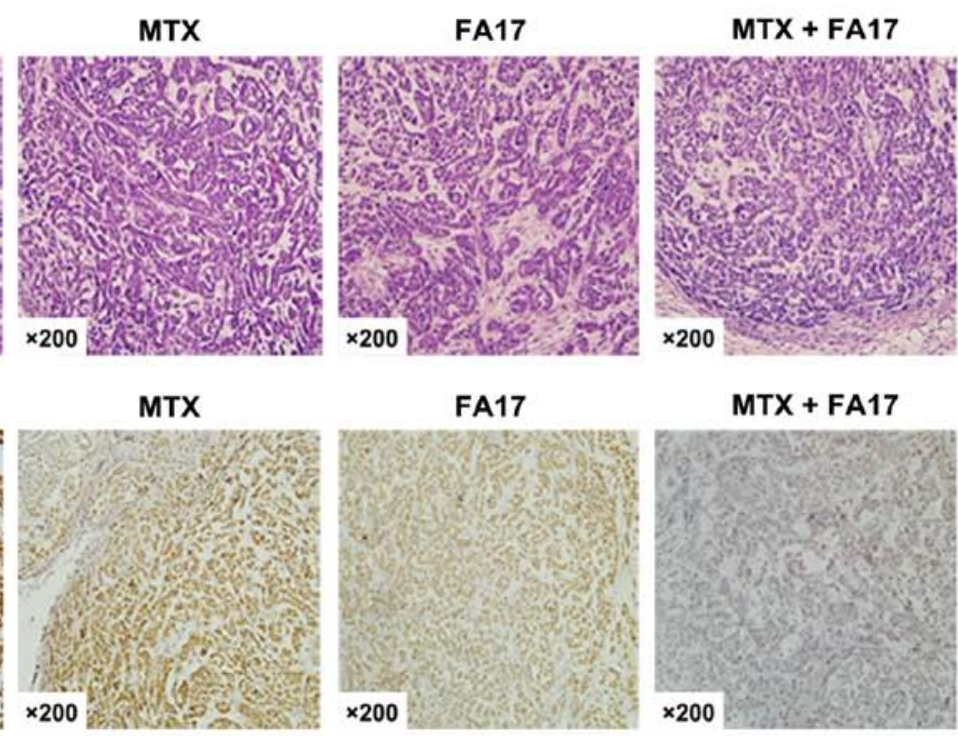

FA17
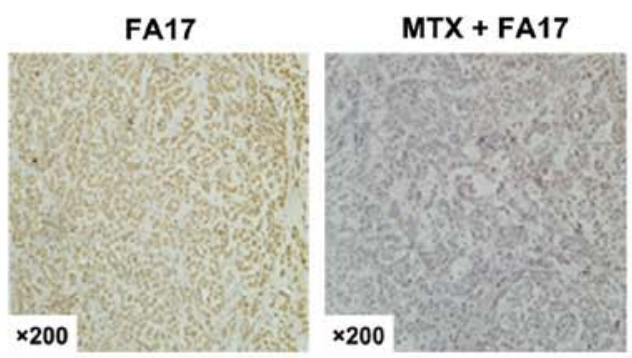

E

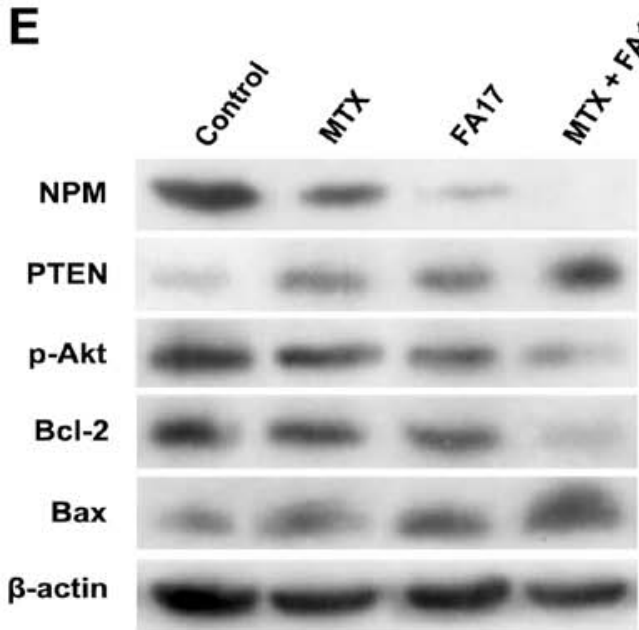


with sensitive cells. Moreover, recent studies have shown that NPM, as non-ribosomal nucleolar phosphoprotein, was high level in a variety of tumors including gastric cancer (28), colon cancer (29), thyroid cancer (30), renal cell carcinoma (31) and even expected as a biomolecular marker for breast cancer (32). In addition, Wang et al (17) found that decreased expression of nucleophosmin/B23 could increase drug sensitivity of adriamycin-resistant Molt-4 leukemia cells. Upregulation of NPM may take part in mechanism of MDR in bladder cancer (10) and resistant leukemic HL-60 cells (11).

NPM was closely correlated with the formation of MDR, but the molecular mechanism of NPM-induced MDR in breast cancer is not clear. We know that the genesis and development of tumor referred to activations of various signaling pathways. There is some evidence that PI3K/Akt pathway was considered to contribute to tumorigenesis, progression and even drug resistance in cancers (19,33-35). Moreover, the study reported that activity of NPM was closely associated with activation of PI3K/Akt signaling pathway $(36,37)$. In this study, we found the effect of negative regulation between NPM and PTEN in MCF-7/MTX cells, which activated the phosphorylation of Akt and suppressed cell apoptosis, and then blocked downstream mitochondrial apoptotic pathway. Similarly, Pianta et al (30) demonstrated that upregulation of NPM was related to an increase of p-Akt level and a decrease of PTEN expression. Further study showed that knockdown of NPM could attenuate the activation of PI3K/Akt pathway and promote the reinforcement of downstream pro-apoptotic effect using siRNA interference. Therefore, these data indicate NPM as a potential resistant target plays an important role in occurrence of MDR in breast cancer. Also we could reverse drug resistance in search of effective reversal agent targeted NPM as a potent therapeutic strategy for MDR in the clinic.

Following the deepening of research in the resistant mechanisms of NPM, another considerable issue was addressed. Investigators discovered that NPM was an important histone chaperone (38), which impacted the function of post-translational modification of histones. In addition, histone deacetylation, as a significant epigenetic modification, was involved in the occurrence and development of many malignant tumors, such as lung cancer, ovarian cancer, breast cancer, colon cancer, pancreatic cancer and leukemia (39-45). Therefore, the effective histone deacetylase inhibitor offered a promising strategy for cancer therapy and it may be a potential reversal agent of tumor resistance $(13,46,47)$. We screened out a novel synthetic histone deacetylase inhibitor FA17 that possessed strongly antitumor activity (15), which could reduce the MDR of breast cancer cells by altering the cycle distribution of MCF-7/MTX, enhancing methotrexateinduced cell apoptosis and downregulating related factors of MDR. Furthermore, downregulation of NPM level and inhibition of PI3K/Akt signaling pathway were both observed in MCF-7/MTX cells and xenograft tumors after FA17 treatment, which initiated the downstream apoptotic program. Therefore, it is apparent that FA17 has potent ability to reverse drug resistance in breast cancer, and it probably demonstrates the underlying reversal mechanism by suppressing NPM level to increase PTEN expression and inactivates PI3K/Akt pathway. These results indicate FA17 could be an effective candidate compound for reversing breast cancer resistance.
In conclusion, the potential resistant target NPM was significantly highly expressed in MCF-7/MTX cells, and its molecular mechanisms of NPM induced MDR by activation of PI3K/Akt pathway and suppression of mitochondrial apoptosis pathway in breast cancer cells. Based on drugresistant marker NPM, histone deacetylase inhibitor FA17, as an effective reversal agent, was screened out in MCF-7/MTX cells. We illuminated reversal mechanisms of FA17 acting on drug resistance of breast cancer, which could reverse MDR through decreasing NPM to accelerate PTEM level, devitalizing PI3K/Akt pathway and enhancing resistant cell apoptosis in vitro and in vivo. These finding of the inhibitory effect on NPM might provide therapeutic strategy and scientific evidence for improving clinical drug resistance, and the preclinical evaluation of effective reversal agent FA17 offers a significant value for clinical application in MDR of breast cancer.

\section{Acknowledgements}

We are grateful to Dr Dalin He and Xinyang Wang for valuable assistance, and Dr Jie Zhang, Hongyan Liu for technical assistance in this study. This study was supported by National Natural Science Foundation of China (no s.81502616 and 81473177).

\section{References}

1. Bray F, Jemal A, Grey N, Ferlay J and Forman D: Global cancer transitions according to the Human Development Index (2008-2030): A population-based study. Lancet Oncol 13: 790-801, 2012.

2. Fan L, Strasser-Weippl K, Li JJ, St Louis J, Finkelstein DM, Yu KD, Chen WQ, Shao ZM and Goss PE: Breast cancer in China. Lancet Oncol 15: e279-e289, 2014.

3. Siegel R, DeSantis C, Virgo K, Stein K, Mariotto A, Smith T, Cooper D, Gansler T, Lerro C, Fedewa S, et al: Cancer treatment and survivorship statistics, 2012. CA Cancer J Clin 62: 220-241, 2012.

4. Baguley BC: Multiple drug resistance mechanisms in cancer. Mol Biotechnol 46: 308-316, 2010.

5. Chen S, Cai J, Zhang W, Zheng X, Hu S, Lu J, Xing J and Dong Y: Proteomic identification of differentially expressed proteins associated with the multiple drug resistance in methotrexateresistant human breast cancer cells. Int J Oncol 45: 448-458, 2014.

6. Borer RA, Lehner CF, Eppenberger HM and Nigg EA: Major nucleolar proteins shuttle between nucleus and cytoplasm. Cell 56: 379-390, 1989.

7. Yung BY: Oncogenic role of nucleophosmin/B23. Chang Gung Med J 30: 285-293, 2007.

8. Lim MJ and Wang XW: Nucleophosmin and human cancer. Cancer Detect Prev 30: 481-490, 2006.

9. Grisendi S, Mecucci C, Falini B and Pandolfi PP: Nucleophosmin and cancer. Nat Rev Cancer 6: 493-505, 2006.

10. Meng Q, Lei T, Zhang M, Zhao J, Zhao XH and Zhang M: Identification of proteins differentially expressed in adriamycinresistant (pumc-91/ADM) and parental (pumc-91) human bladder cancer cell lines by proteome analysis. J Cancer Res Clin Oncol 139: 509-519, 2013.

11. Lin M, Hu J, Liu T, Li J, Chen B and Chen X: Knockdown of nucleophosmin by RNA interference reverses multidrug resistance in resistant leukemic HL-60 cells. Immunobiology 218: 1147-1154, 2013.

12. Swaminathan V, Kishore AH, Febitha KK and Kundu TK: Human histone chaperone nucleophosmin enhances acetylationdependent chromatin transcription. Mol Cell Biol 25: 7534-7545, 2005.

13. Carafa V, Miceli M, Altucci L and Nebbioso A: Histone deacetylase inhibitors: A patent review (2009-2011). Expert Opin Ther Pat 23: 1-17, 2013. 
14. Rao R, Fiskus W, Ganguly S, Kambhampati S and Bhalla KN: HDAC inhibitors and chaperone function. Adv Cancer Res 116: 239-262, 2012.

15. Wang F, Lu W, Zhang T, Dong J, Gao H, Li P, Wang S and Zhang J: Development of novel ferulic acid derivatives as potent histone deacetylase inhibitors. Bioorg Med Chem 21: 6973-6980, 2013.

16. Yang J, Li A, Yang Y and Li X: Identification of cyclophilin A as a potential prognostic factor for clear-cell renal cell carcinoma by comparative proteomic analysis. Cancer Biol Ther 11: 535-546, 2011.

17. Wang L, Chen B, Lin M, Cao Y, Chen Y, Chen X, Liu T and Hu J: Decreased expression of nucleophosmin/B23 increases drug sensitivity of adriamycin-resistant Molt-4 leukemia cells through mdr-1 regulation and Akt/mTOR signaling. Immunobiology 220 : 331-340, 2015

18. Michl P and Downward J: Mechanisms of disease: PI3K/ AKT signaling in gastrointestinal cancers. Z Gastroenterol 43: $1133-1139,2005$

19. Gao AM, Ke ZP, Wang JN, Yang JY, Chen SY and Chen H: Apigenin sensitizes doxorubicin-resistant hepatocellular carcinoma BEL-7402/ADM cells to doxorubicin via inhibiting PI3K/Akt/Nrf2 pathway. Carcinogenesis 34: 1806-1814, 2013.

20. Gray MJ, Mhawech-Fauceglia P, Yoo E, Yang W, Wu E, Lee AS and Lin YG: AKT inhibition mitigates GRP78 (glucose-regulated protein) expression and contribution to chemoresistance in endometrial cancers. Int J Cancer 133: 21-30, 2013.

21. Xie X, Tang B, Zhou J, Gao Q and Zhang P: Inhibition of the PI3K/Akt pathway increases the chemosensitivity of gastric cancer to vincristine. Oncol Rep 30: 773-782, 2013.

22. Saeki T, Tsuruo T, Sato W and Nishikawsa K: Drug resistance in chemotherapy for breast cancer. Cancer Chemother Pharmaco 56 (Suppl 1): 84-89, 2005

23. Pritchard AL and Hayward NK: Molecular pathways: Mitogenactivated protein kinase pathway mutations and drug resistance. Clin Cancer Res 19: 2301-2309, 2013.

24. Cassinelli G, Zuco V, Gatti L, Lanzi C, Zaffaroni N, Colombo D and Perego P: Targeting the Akt kinase to modulate survival, invasiveness and drug resistance of cancer cells. Curr Med Chem 20: 1923-1945, 2013.

25. Jayashree BS, Nigam S, Pai A, Patel HK, Reddy ND, Kumar N and Rao CM: Targets in anticancer research - A review. Indian J Exp Biol 53: 489-507, 2015.

26. Pan MH, Chiou YS, Chen LH and Ho CT: Breast cancer chemoprevention by dietary natural phenolic compounds: Specific epigenetic related molecular targets. Mol Nutr Food Res 59: 21-35, 2015.

27. Di Leo A, Curigliano G, Diéras V, Malorni L, Sotiriou C, Swanton C, Thompson A, Tutt A and Piccart M: New approaches for improving outcomes in breast cancer in Europe. Breast 24: 321-330, 2015

28. Ding A, Zhao W, Shi X, Yao R, Zhou F, Yue L, Liu S and Qiu W: Impact of NPM, TFF3 and TACC1 on the prognosis of patients with primary gastric cancer. PLoS One 8: e82136, 2013.

29. Nozawa Y, Van Belzen N, Van der Made AC, Dinjens WN and Bosman FT: Expression of nucleophosmin/B23 in normal and neoplastic colorectal mucosa. J Pathol 178: 48-52, 1996.

30. Pianta A, Puppin C, Franzoni A, Fabbro D, Di Loreto C, Bulotta S, Deganuto M, Paron I, Tell G, Puxeddu E, et al: Nucleophosmin is overexpressed in thyroid tumors. Biochem Biophys Res Commun 397: 499-504, 2010

31. Sari A, Calli A, Altinboga AA, Pehlivan FS, Gorgel SN, Balci U, Ermete M, Dincel C and Cakalagaoglu F: Nucleophosmin expression in renal cell carcinoma and oncocytoma. APMIS 120: $187-194,2012$

32. Nicolini A, Carpi A and Tarro G: Biomolecular markers of breast cancer. Front Biosci 11: 1818-1843, 2006.
33. Yap TA, Bjerke L, Clarke PA and Workman P: Drugging PI3K in cancer: Refining targets and therapeutic strategies. Curr Opin Pharmacol 23: 98-107, 2015.

34. Hsu HH, Cheng LH, Ho TJ, Kuo WW, Lin YM, Chen MC, Lee NH, Tsai FJ, Tsai KH and Huang CY: Apicidin-resistant HA22T hepatocellular carcinoma cells massively promote prosurvival capability via IGF-IR/PI3K/Akt signaling pathway activation. Tumour Biol 35: 303-313, 2014.

35. Burris HA III: Overcoming acquired resistance to anticancer therapy: Focus on the PI3K/AKT/mTOR pathway. Cancer Chemother Pharmacol 71: 829-842, 2013.

36. Slupianek A, Nieborowska-Skorska M, Hoser G, Morrione A, Majewski M, Xue L, Morris SW, Wasik MA and Skorski T: Role of phosphatidylinositol 3-kinase-Akt pathway in nucleophosmin/ anaplastic lymphoma kinase-mediated lymphomagenesis. Cancer Res 61: 2194-2199, 2001.

37. Bai RY, Ouyang T, Miething C, Morris SW, Peschel C and Duyster J: Nucleophosmin-anaplastic lymphoma kinase associated with anaplastic large-cell lymphoma activates the phosphatidylinositol 3-kinase/Akt antiapoptotic signaling pathway. Blood 96: 4319-4327, 2000

38. Eitoku M, Sato L, Senda T and Horikoshi M: Histone chaperones: 30 years from isolation to elucidation of the mechanisms of nucleosome assembly and disassembly. Cell Mol Life Sci 65: 414-444, 2008

39. Shi YK, Li ZH, Han XQ, Yi JH, Wang ZH, Hou JL, Feng CR, Fang QH, Wang HH, Zhang PF, et al: The histone deacetylase inhibitor suberoylanilide hydroxamic acid induces growth inhibition and enhances taxol-induced cell death in breast cancer. Cancer Chemother Pharmacol 66: 1131-1140, 2010.

40. Balch C, Naegeli K, Nam S, Ballard B, Hyslop A, Melki C, Reilly E, Hur MW and Nephew KP: A unique histone deacetylase inhibitor alters microRNA expression and signal transduction in chemoresistant ovarian cancer cells. Cancer Biol Ther 13: 681-693, 2012.

41. Venkannagari S, Fiskus W, Peth K, Atadja P, Hidalgo M, Maitra A and Bhalla KN: Superior efficacy of co-treatment with dual PI3K/mTOR inhibitor NVP-BEZ235 and pan-histone deacetylase inhibitor against human pancreatic cancer. Oncotarget 3 : 1416-1427, 2012.

42. Kang MR, Lee K, Kang JS, Lee CW, Lee KH, Kim JH, Yang JW, Kim BG, Han G, Kang JS, et al: KBH-A42, a histone deacetylase inhibitor, inhibits the growth of doxorubicin-resistant leukemia cells expressing P-glycoprotein. Oncol Rep 23: 801-809, 2010.

43. Edmond V, Brambilla C, Brambilla E, Gazzeri S and Eymin B: SRSF2 is required for sodium butyrate-mediated p21(WAF1) induction and premature senescence in human lung carcinoma cell lines. Cell Cycle 10: 1968-1977, 2011.

44. Bártová E, Pacherník J, Harnicarová A, Kovarík A, Kovaríková M, Hofmanová J, Skalníková M, Kozubek M and Kozubek S: Nuclear levels and patterns of histone $\mathrm{H} 3$ modification and HP1 proteins after inhibition of histone deacetylases. J Cell Sci 118: 5035-5046, 2005.

45. Del Bufalo D, Desideri M, De Luca T, Di Martile M, Gabellini C, Monica V, Busso S, Eramo A, De Maria R, Milella M, et al: Histone deacetylase inhibition synergistically enhances pemetrexed cytotoxicity through induction of apoptosis and autophagy in non-small cell lung cancer. Mol Cancer 13: 230, 2014

46. Wu Q, Cheng Z, Zhu J, Xu W, Peng X, Chen C, Li W, Wang F, Cao L, Yi X, et al: Suberoylanilide hydroxamic acid treatment reveals crosstalks among proteome, ubiquitylome and acetylome in non-small cell lung cancer A549 cell line. Sci Rep 5: 9520 , 2015.

47. Atadja PW: HDAC inhibitors and cancer therapy. Prog Drug Res 67: 175-195, 2011. 